\title{
EFFICACY EVALUATION OF SOME ANTIBIOTICS AGAINST SYRIAN BRUCELLA SPP ISOLATES, IN VITRO
}

\author{
Mazen Safi*; Ayman Al-Mariri
}

Department of Molecular Biology and Biotechnology, Atomic Energy Commission, P.O. Box 6091, Damascus, Syria.

Submitted: February 03, 2011; Returned to authors for corrections: November 25, 2011; Approved: June 07, 2012.

\begin{abstract}
Brucellosis is an endemic zoonosis in Syria, affecting large numbers of animals and there are an increasing number of cases in humans. The aim of this study is to investigate the in vitro efficacy of various traditional and new antibiotics against 89 Brucella isolates (isolated from domestic animals) collected from different Syrian regions. Minimum inhibitory concentrations (MICs) of seventeen antibiotics were determined. Ciprofloxacin and ofloxacin were the most effective antibiotics, whereas sparfloxacin, levofloxacin, doxycycline and tetracycline had a moderate activity. In contrast, moxifloxacin and rifampicin had a low activity, while streptomycin, spiramycin and cephalosporines were ineffective. As a result, we come to the conclusion that a combination between one effective quinolone and doxycycline has a good efficacy against
\end{abstract} Brucella. Further in vivo studies are necessary to support this suggestion.

Key words: Antibiotics, Brucella, quinolones

\section{INTRODUCTION}

Brucella is a facultative intracellular pathogen, a family of small, nonmotile, gram-negative coccobacilli, that causes abortion in domestic animals (sheep, cattle, and goats), and a febrile illness ("undulant fever") in humans $(8,9)$. In Syria, it affects a large number of animals and an increasing number of cases in humans. The last recommendation by the World Health Organization (WHO) for the treatment of human acute brucellosis in adults suggested 600 to $900 \mathrm{mg}$ rifampicin and $200 \mathrm{mg}$ doxycycline daily for a minimum of 6 weeks, or doxycycline for 6 weeks plus streptomycin for 2-3 weeks (4). However, the relapse rates associated with doxycycline/ rifampicin and doxycycline/streptomycin regimens are 4.6-
$24 \%$ and 5-8\%, respectively (27).

The combination between the rifampicin and trimethoprim-sulfomethoxazole is the suggested regimen for children $(3,15,16)$. Triple-antibiotic combinations were found to be of value in some cases of brucellar endocarditis, meningitis, and spondylitis $(2,21,31)$. Fluoroquinolones are an alternative. Only in vitro observations exist for moxifloxacin and levofloxacin (19), whereas various combinations that incorporate ciprofloxacin and ofloxacin have been tried clinically, yielding similar efficacy to that of the classic regimens (13). Fluoroquinolones have good anti-brucellosis activity in vitro $(1,18,25)$ and reach high intracellular concentrations.

Brucella isolates are generally considered susceptible to 
the antibiotics that are recommended by the WHO. Nevertheless, sporadic cases of a kind of antibiotic resistance have been reported $(6,19)$. The aim of this study is to determine the susceptibility of doxycycline, rifampicin, tetracycline, streptomycin, spiramycin, amoxicillin, flucloxacillin, cefixime, cefprozil, cefotaxime, ceftazidime, cefazolin, ciprofloxacin, levofloxacin, ofloxacin, moxifloxacin and sparfloxacin against the Brucella isolates identified in the Laboratory of Molecular Biology and Biotechnology, Atomic Energy Commission, Syria, collected from milk samples over different provinces.

\section{MATERIALS AND METHODS}

\section{Microorganisms and growth conditions}

Eighty nine brucella isolates were collected prospectively between 2004 and 2007 from bovine and ovine milk from different Syrian provinces. Syrian territories were divided into four regions as follows: Northern region (including: AlHasakah, Dir-Alzour, Al-Rakah and Aleppo provinces); Central region (including: Edleb, Hama and Homs provinces); Coastal region (including: Tartous and Lattakia provinces) and Southern region (including: Al-Quonaitra, Daraa, Al-Souaida, Damascus and Damascus rural provinces). Bacteria were isolated from milk cultures at the Immunology and Microbiology Laboratory, AECS (5). Brucella was grown under optimal conditions in $2 \mathrm{YT}$ agar $\{$ Difco, BD, USA (peptone [10 g], sodium chloride [5 g], meat extract [5 g], agar [20 g], distilled water [1 litre]) $\}$ at $37^{\circ} \mathrm{C}$ in a water bath (Grant, Cambridge, UK) to ensure sufficient cell density. Following antibiotics (Oxoid, UK) were added to inhibit the growth of organisms other than Brucella, cycloheximide (100 mg), bacitracin (25000 units), polymyxin B sulphate (5000 units), vancomycin (20 mg), nalidixic acid (5 $\mathrm{mg})$ and nystatin (100000 units). To prepare the solid selective media, basal medium was melted and then cooled to $56^{\circ} \mathrm{C}$ in a water bath and stock solutions of the antibiotics added with $5 \%$ of horse serum (PAN-Biotech, Gmbh, Germany). The biotyping of the bacteria used the following tests: $\mathrm{CO}_{2}$ requirement, $\mathrm{H}_{2} \mathrm{~S}$ production, urease and oxidase positivity, growth in the presence of dyes (thionine and basic fuchsine), and reaction with monospecific anti-A and anti-M sera (Arcomex, Jordan). Strains identified as B. melitensis ( 81 isolates) or B. abortus (8 isolates) were stored in $2 \mathrm{YT}$ medium at $-20^{\circ} \mathrm{C}$ until susceptibility testing. During the experiment, laboratory workers were wearing impermeable protective clothes, gloves, and face masks.

\section{Antibiotics susceptibility testing}

In order to estimate the antibiotics susceptibility, well broth microdilution method was used with 96-well plates, (TPP, Switzerland). Antibiotics were twofold diluted in Brucella broth $^{\circledR}$ (acumedia $^{\circledR}$, Michigan, USA) and wells were inoculated with $10^{6} \mathrm{CFU}$ of bacteria (in a $0.2 \mathrm{ml}$ final volume). The incubation period was $48 \mathrm{~h}$ at $37^{\circ} \mathrm{C}$. MIC testing was performed according to the recommendations of the CLSI (22). Unsupplemented brucella broth media were used. The $\mathrm{pH}$ of the broth was adjusted to a range of $7.1 \pm 0.1$. The range of concentrations assayed for each antibiotic was 0.07 to 100 $\mu \mathrm{g} / \mathrm{ml}$. The lowest concentration that completely inhibited visual growth was recorded and interpreted as the MIC. The absorbance was determined at $590 \mathrm{~nm}$ (Thermo-lab Systems Reader, Finland). All tests were performed in triplicate and then averaged.

Investigated antibiotics were the following: doxycycline (Sigma, St. Louis, USA), rifampicin (Sigma), tetracycline (Sigma-Aldrich, USA), streptomycin (Sigma), spiramycin (Sigma), amoxicillin (Fluka, Sigma-Aldrich, USA), flucloxacillin (Square Pharma, Bangladish), cefixime (Fluka, Sigma-Aldrich, USA), cefprozil (Bristol-Myers Squibb, NewYork, USA), cefotaxime (Sigma), ceftazidime (Sigma), cefazolin (Fluka, Sigma-Aldrich, USA), ciprofloxacin (Bayer, Istambul, Turkey), levofloxacin (Sigma), ofloxacin (Sigma), moxifloxacin (Bayer, Istambul, Turkey) and sparfloxacin (Sigma).

A well containing no antibiotics was also employed. 
Plates were incubated in the conditions mentioned above.

\section{RESULTS}

The $\mathrm{MIC}_{\text {range }}, \mathrm{MIC}_{50}$ and $\mathrm{MIC}_{90}$ values of the antibiotics are shown in Table 1. No activity was observed at all Syrian regions when the following antibiotics were used: streptomycin, spiramycin, amoxicillin, flucloxacillin, cefixime, cefprozil, cefotaxime, ceftazidime, and cefazoline. Almost all the isolates were resistant to these antibiotics. The $\mathrm{MIC}_{\text {range }}$ values of doxycycline and tetracycline were low against the isolates collected from central region $(0.3-0.75 \mu \mathrm{g} / \mathrm{ml}$ and 0.15 $0.75 \mu \mathrm{g} / \mathrm{ml}$, respectively), and moderate to high against that collected from the other regions. Whereas, $\mathrm{MIC}_{\text {range }}$ values of rifampicin were very high against the isolates collected from all regions (from 1.5-6.25 $\mu \mathrm{g} / \mathrm{ml}$ against isolates collected from southern and central regions, to $25-50 \mu \mathrm{g} / \mathrm{ml}$ against that collected from northern region. Among the quinolones, ciprofloxacin was the most effective against the isolates collected from all regions ( $\mathrm{MIC}_{\text {range }}: 0.07-6.25 \mu \mathrm{g} / \mathrm{ml}$; from 0.07-0.3 $\mu \mathrm{g} / \mathrm{ml}$ against isolates collected from northern region to $0.75-6.25 \mu \mathrm{g} / \mathrm{ml}$ against that collected coastal region), and moxifloxacin had the highest $\mathrm{MIC}_{\text {range }}$. Other than ciprofloxacin, the $\mathrm{MIC}_{\text {range }}$ of ofloxacin was the lowest, particularly against the isolates collected from northern region $(0.07-0.75 \mu \mathrm{g} / \mathrm{ml})$, but it was moderate to high against that collected from the other regions. Levofloxacin and sparfloxacin had moderate activities against the isolates collected from all regions.

Table 1. MICs values of antibiotics against Syrian isolates collected from different regions. Efficacy evaluation of some antibiotics against Syrian Brucella spp isolates, in vitro. (Safi and AL-Mariri)

\begin{tabular}{|c|c|c|c|c|c|c|c|c|c|c|c|c|}
\hline & \multicolumn{3}{|c|}{$\begin{array}{c}\text { MICs at Northern region } \\
(\mu \mathrm{g} / \mathrm{ml})\end{array}$} & \multicolumn{3}{|c|}{$\begin{array}{c}\text { MICs at Costal region } \\
(\mu \mathrm{g} / \mathrm{ml})\end{array}$} & \multicolumn{3}{|c|}{$\begin{array}{c}\text { MICs at Central region } \\
(\mu \mathrm{g} / \mathrm{ml})\end{array}$} & \multicolumn{3}{|c|}{$\begin{array}{c}\text { MICs at Southern region } \\
(\mu \mathrm{g} / \mathrm{ml})\end{array}$} \\
\hline & $\mathrm{MIC}_{\text {range }}$ & $\mathrm{MIC}_{50}$ & $\mathrm{MIC}_{90}$ & $\mathrm{MIC}_{\text {range }}$ & $\mathrm{MIC}_{50}$ & $\mathrm{MIC}_{90}$ & $\mathrm{MIC}_{\text {range }}$ & $\mathrm{MIC}_{50}$ & $\mathrm{MIC}_{90}$ & $\mathrm{MIC}_{\text {range }}$ & $\mathrm{MIC}_{50}$ & $\mathrm{MIC}_{90}$ \\
\hline Doxycycline & $0.3-6.25$ & 0.75 & 3 & $6.25-12.5$ & 6.25 & 12.5 & $0.3-0.75$ & 0.75 & 0.75 & $0.75-3$ & 0.75 & 3 \\
\hline Rifampicin & $25-50$ & 25 & 50 & $25-50$ & 25 & 50 & $1.5-3$ & 3 & 3 & $1.5-6.25$ & 3 & 6.25 \\
\hline Tetracycline & $1.5-12.5$ & 6.25 & 12.5 & $6.25-12.5$ & 6.25 & 12.5 & $0.15-0.75$ & 0.3 & 0.75 & $0.75-6.25$ & 1.5 & 6.25 \\
\hline Streptomycin & $50->100$ & 100 & $>100$ & $>100$ & $>100$ & $>100$ & $>100$ & $>100$ & $>100$ & $50->100$ & 100 & $>100$ \\
\hline Spiramycin & $>100$ & $>100$ & $>100$ & $>100$ & $>100$ & $>100$ & $>100$ & $>100$ & $>100$ & $>100$ & $>100$ & $>100$ \\
\hline Amoxicillin & $>100$ & $>100$ & $>100$ & $>100$ & $>100$ & $>100$ & $>100$ & $>100$ & $>100$ & $>100$ & $>100$ & $>100$ \\
\hline Flucloxacillin & $>100$ & $>100$ & $>100$ & $>100$ & $>100$ & $>100$ & $>100$ & $>100$ & $>100$ & $>100$ & $>100$ & $>100$ \\
\hline Cefixime & $>100$ & $>100$ & $>100$ & $50->100$ & 100 & $>100$ & $50->100$ & 100 & $>100$ & $>100$ & $>100$ & $>100$ \\
\hline Cefprozil & $12.5->100$ & 25 & 100 & $6.25->100$ & 12.5 & 100 & $12.5->100$ & 25 & 100 & $>100$ & $>100$ & $>100$ \\
\hline Cefotaxime & $12.5->100$ & 25 & 100 & $6.25->100$ & 12.5 & 100 & $12.5->100$ & 25 & $>100$ & $>100$ & $>100$ & $>100$ \\
\hline Ceftazidime & $25-100$ & 50 & 100 & $6.25->100$ & 12.5 & 100 & $6.25-100$ & 25 & 100 & $>100$ & $>100$ & $>100$ \\
\hline Cefazolin & $12.5-50$ & 12.5 & 25 & $12.5->100$ & 25 & $>100$ & $6.25-50$ & 12.5 & 25 & $50->100$ & 50 & $>100$ \\
\hline Ciprofloxacin & $0.07-0.3$ & 0.07 & 0.3 & $0.75-6.25$ & 1.5 & 3 & $0.3-0.75$ & 0.75 & 0.75 & $0.15-1.5$ & 0.75 & 1.5 \\
\hline Levofloxacin & $0.75-12.5$ & 1.5 & 6.25 & $0.15-25$ & 0.75 & 25 & $0.75-6.25$ & 1.5 & 3 & $0.3-6.25$ & 0.75 & 6.25 \\
\hline Ofloxacin & $0.07-0.75$ & 0.15 & 0.75 & $0.15-50$ & 0.75 & 25 & $0.15-12.5$ & 0.75 & 6.25 & $0.3-6.25$ & 0.75 & 3 \\
\hline Moxifloxacin & $0.75-50$ & 6.25 & 50 & $12.5-100$ & 25 & 100 & $1.5-50$ & 12.5 & 50 & $12.5-100$ & 25 & $>100$ \\
\hline Sparfloxacin & $0.15-12.5$ & 0.75 & 12.5 & $1.5-100$ & 3 & 50 & $0.15-12.5$ & 0.3 & 6.25 & $3-12.5$ & 6.25 & 12.5 \\
\hline
\end{tabular}

\section{DISCUSSION}

Treatment of human brucellosis needs antibiotics that can penetrate macrophages and can act in the acidic intracellular environment. Brucella is considered to be susceptible to the antibiotics recommended by the WHO for treatment of brucellosis. Relapses, at a rate of about 10 percent, usually occur in the first year after the infection, but they are caused in most cases by inadequate treatment (24). Strains resistant to the main antimicrobial agents may emerge and lead on to treatment inhibition (20).

The isolates included in this work were collected from different areas of Syrian cities. They were totally resistant against streptomycin, macrolide (spiramycin), amoxicillin, flucloxacillin, and against all cephalosporins used in this work (including: cefixime, cefprozil, cefotaxime, ceftazidime, and 
cefazolin). This result did not concord, in part, with that found by Palenque et al. (23); where they found that cefotaxime was among the most effective agents tested, with MICs ranging from 0.25 to $2 \mu \mathrm{g} / \mathrm{ml}$. However, it concords with the result of ceftazidime where the MICs was between 4 and $64 \mu \mathrm{g} / \mathrm{ml}$.

All the isolates were susceptible to tetracycline, the $\mathrm{MIC}_{\text {range }}$ of this antibiotic was very low, particularly against the isolates collected from the central region $(0.15-0.75 \mu \mathrm{g} / \mathrm{ml})$. This finding agrees with previous reports $(6,7,16,30)$.

In addition, doxycyline had a very good activity against all isolates, with a $\mathrm{MIC}_{\text {range }}$ of $0.3-0.75 \mu \mathrm{g} / \mathrm{ml}$ in the coastal region; whereas, rifampicin showed a very low activity against almost all isolates. On the other hand, eleven isolates were totally resistant to rifampicin. This finding did not agree with that found by Turkmani et al. (29). However, Baykam et al. (6) and Dimitrov et al. (10) found that $9.6 \%$ and $8 \%$ of the isolates were resistant to rifampicin in vitro, respectively.

Most studies that examined the use of quinolones against B. melitensis showed, generally, low MICs values; where the $\mathrm{MIC}_{90}$ to the ofloxacin was $0.02-2.5 \mathrm{mg} / \mathrm{l}(11,14,17)$; to the levofloxacin $0.5 \mathrm{mg} / \mathrm{l}(17,28)$; to the sparfloxacin $0.12-2 \mathrm{mg} / 1$ $(11,12,26)$; to the ciprofloxacin $0.06-2 \mathrm{mg} / 1(7,17,19)$; and to the moxifloxacin $0.5-1 \mathrm{mg} / \mathrm{l}(19,28)$. However, among the quinolones that are used in our study, ciprofloxacin revealed the lowest $\mathrm{MIC}_{\text {range }}$ against the isolates collected from all Syrian regions $\left(\mathrm{MIC}_{\text {range }}\right.$ 0.07-6.25 $\mu \mathrm{g} / \mathrm{ml}$ ), and moxifloxacin showed the highest $\mathrm{MIC}_{\text {range }}\left(\mathrm{MIC}_{\text {range }} 1.5-100 \mu \mathrm{g} / \mathrm{ml}\right)$.

In conclusion, among the antibiotics used in this study, quinolones were the most effective agents against Syrian brucella isolates. Ciprofloxacin and ofloxacin showed a very good activity; sparfloxacin and levofloxacin were quite active, whereas, moxifloxacin had limited effects. Further and more specific studies, in vivo, are much recommended to determine the efficacy of quinolones in the treatment of brucellosis infections.

On the other hand, doxycycline and tetracycline had a quite good activity. Since rifampicin is commonly used for prevalent diseases such as tuberculosis, the regional susceptibility pattern of rifampicin should be assessed periodically.

Spiramycin, amoxicillin and cephalosporins were included in this study for research purposes only, as those agents are ineffective in vivo for brucellosis treatment.

\section{ACKNOWLEDGEMENTS}

The authors would like to thank the Director General of the AECS and the Head of the Molecular Biology and Biotechnology Department for their support.

\section{REFERENCES}

1. Akalin, H.; Unal, S.; Gur, D.; Baykai, M. (1990). Ofloxacin in the treatment of brucellosis. Eur. J. Clin. Microbiol. Dis. 3, 326-328.

2. Akdeniz, H.; Irmark, H.; Anlar, O.; Demiroz, A.P. (1998). Central nervous system brucellosis:presentation, diagnosis and treatment. $J$. Infect. 36, 297-301.

3. Al Eissa, Y.A.; Kambal, A.M.; al Nasser, M.N.; al Habib, S.A.; al Fawaz, I.M.; al Zamil, F.A. (1990). Childhood brucellosis:a study of 102 cases. Pediatr Infect. Dis. J. 9, 74-79.

4. Anonymous. (1986). Joint FAO/WHO expert committee on brucellosis. WHO Tech. Rep. Ser. 740, 1-132.

5. Almariri, A. (2008). Ultraviolet C lethal effect on Brucella melitensis. New Microbiologica. 31, 47-55.

6. Baykam, N.; Esener, H.; Ergonul, O.; Eren, S.; Celikbas, A.K.; Dokuzoguz, B. (2004). In vitro antimicrobial susceptibility of Brucella species. Intern. J. Antimicrob. Agents. 23, 405-407.

7. Bodur, H.; Balaban, N.; Aksaray, S.; Yetener, V.; Akinci, E.; Colpan, A.; Erbay, A. (2003). Biotypes and antimicrobial susceptibilities of Brucella isolates. Scand. J. Infect. Dis. 35, 337-338.

8. Corbel, M.J. (1997). Brucellosis: an overview. Emerg. Infect. Dis. 3, 213-321.

9. DelVecchio, V.G.; Kapatral, V.; Redkar, R.J.; Patra, G.; Mujer, C.; Los, T.; Ivanova, N.; Anderson, I.; Bhattacharyya, A.; Lykidis, A.; Reznik, G.; Jablonski, L.; Larsen, N.; D'Souza, M.; Bernal, A.; Mazur, M.; Goltsman, E.; Selkov, E.; Elzer, P.H.; Hagius, S.; O'Callaghan, D.; Letesson, J.J.; Haselkorn, R.; Kyrpides, N.; Overbeek, R. (2002). The genome sequence of the facultative intracellular pathogen Brucella melitensis. Proc. Natl. Acad. Sci. USA. 99, 443-8.

10. Dimitrov, T.; Panigrahi, D.; Emara, M.; Awni, F.; Passadilla, R. (2004). Seroepidemiological and microbiological study of brucellosis in Kuwait. Med. Princ. Pract.13, 215-219. 
11. Garcia-Rodriguez, J.A.; Garcia-Sanchez, J.E.; Trujillano, I. (1991). Lack of effective bactericidal activity of new quinolones against Brucella spp. Antimicrob. Agents Chemother. 35, 756-759.

12. Garcia-Rodriguez, J.A.; Garcia-Sanchez, J.E.; Trujillano-Martin, I.; Garcia-Sanchez, E.; Garcia-Garcia, M.I.; Fresnadillo, M.J. (1994). Activity of BAY y 3118, a novel 4-quinolone, against Brucella melitensis. J. Chemother. 6, 102-106.

13. Karabay, O.; Sencan, I.; Kayas, D.; Sahin, I. (2004). Ofloxacin plus rifampicin versus doxycycline plus rifampicin in the treatment of brucellosis: arandomized clinical trail [ISRCTN11871179]. BMC Infct. Dis. 4, 18.

14. Khan, M.Y.; Dizon, M.; Kiel, F.W. (1989). Comparative in vitro activities of ofloxacin, difloxacin, ciprofloxacin, and other selected antimicrobial agents against Brucella melitensis. Antimicrob. Agents Chemother. 33, 1409-1410.

15. Khuri-Bulos, N.A.; Daoud, A.H.; Azab, S.M. (1993). Treatment of childhood brucellosis:results of a prospective trail on 113 children. Pediatr Infect. Dis. J. 12, 377-381.

16. Kilic, S.; Dizbay, M.; Hizel, K.; Arman, D. (2008). In vitro synergistic activity of antibiotic combinations against Brucella melitensis using Etest methodology. Braz. J. Microbiol., 39, 1-7.

17. Kocagoz, S.; Akova, M.; Altun, B.; Gur, D.; Hascelik, G. (2002). In vitro activities of new quinolones against Brucella melitensis isolated in a tertiarycare hospital in Turkey. Clin. Microbiol. Infect. 8, 240-242.

18. Lang, R.; Rubinistein, E. (1992). Quinolones for the treatment of brucellosis. J. Antimicrob. Chemother. 29, 357-363.

19. Lopez-Merino, A.; Contreras-Rodriguez, A.; Megranas-Ortiz, R.; Orranita-Gradin, G.M.; Hernandez-Oliva, A.; Gutierrez-Rubio, T.; Cardeñosa, O. (2004). Susceptibility of Mexican brucella isolates to moxifloxacin, ciprofloxacin and other antimicrobials used in the treatment of human brucellosis. Scand. J. Infect. Dis. 36, 636-638.

20. Marianelli, C.; Ciuchini, F.; Tarantino, M.; Pasquali, P.; Adone, R. (2004). Genetic bases of the rifampin resistance phenotype in Brucella spp. J. Clin. Microbiol. 42, 5439-5443.

21. Mert, A.; Kocak, F.; Ozaras, R.; Tabak, F.; Bilir, M.; Kucukugulu, S.; Ozturk, R,; Aktuglu, Y. (2002). The role of antibiotic treatment alone for the management of Brucella endocarditis in adults:a case report and literature review. Ann. Thorac. Cardiovascu. Surg. 8, 381-385.

22. National Committee for Clinical Laboratory Standards. (2003). Methods for dilution antimicrobial susceptibility tests for bacteria that grow aerobically. Approved standard M7-A6. National Committee for Clinical Laboratory Standards, Wayne, Pa.

23. Palenque, E., Otero, J.R.; Noregia, A.R. (1986). In vitro Susceptibility of Brucella melitensis to New Cephalosporins Crossing the Blood-Brain Barrier. J. Antimicrob. Chemother. P, 182-183.

24. Pappas, G.; Akritidis, N.; Bosilkovski, M.; Tsianos, E. (2005). Brucellosis. N. Engl. J. Med. 352, 2325-2336.

25. Qadri, S.M.H.; Akhter, J.; Ueno, Y.; Saldin, H. (1993). In vitro activity of 8 fluoroquinolones against clinical isolates of Brucella melitensis. Ann. Saudi. Med. 13, 37-40.

26. Qadri, S.M.; Halim, A.; Uneo, Y.; Abumustafa, M.; Postle, A.G. (1995). Antibacterial activity of azithromycin against Brucella melitensis. Chemotherapy (Basel). 41, 253-256.

27. Roushan, M.R.H.; Mohraz, M.; Hajlahmadi, M.; Ramzani, A.; Valayati, A.A. (2006). Efficacy of gentamicin plus doxycycline versus streptomycin plus doxycycline in the treatment of brucellosis in humans. Clin. Infct. Dis. 42, 1075-1080.

28. Trujillano-Martin, I.; Garcia-Sanchez, E.; Martinez, I.M.; Fresnadillo, M.J; Garcia-Sanchez, J.E.; Garcia-Rodriguez, J.A. (1999). In vitro activities of six new fluoroquinolones against Brucella melitensis. Antimicrob. Agents Chemother. 43, 194-195.

29. Turkmani, A.; Ioannidis, A.; Christidou, A.; Psaroulaki, A.; Loukaides, F.; Tselentis, Y. (2006). In vitro susceptibilities of Brucella melitensis isolates to eleven antibiotics. Ann. Clin. Microbiol. Antimicrob. 5, 24-29.

30. Yamazham, T.; Aydemir, S.; Tunger, A.; Serter, D.; Gokengin, D. (2005). In vitro activities of various antimicrobials against Brucella melitensis strains in the Aegean region in Turkey. Med. Princ. Pract. 14, 413-416.

31. Yilmaz, E.; Parlak, M.; Akalin, H.; Heper, Y.; Ozakin, C.; Mistik, R.; Oral, B.; Helvaci, S.; Töre, O. (2004). Brucellar spondylitis. Review of 25 cases. J. Clin. Rheumatol. 10, 300-307. 